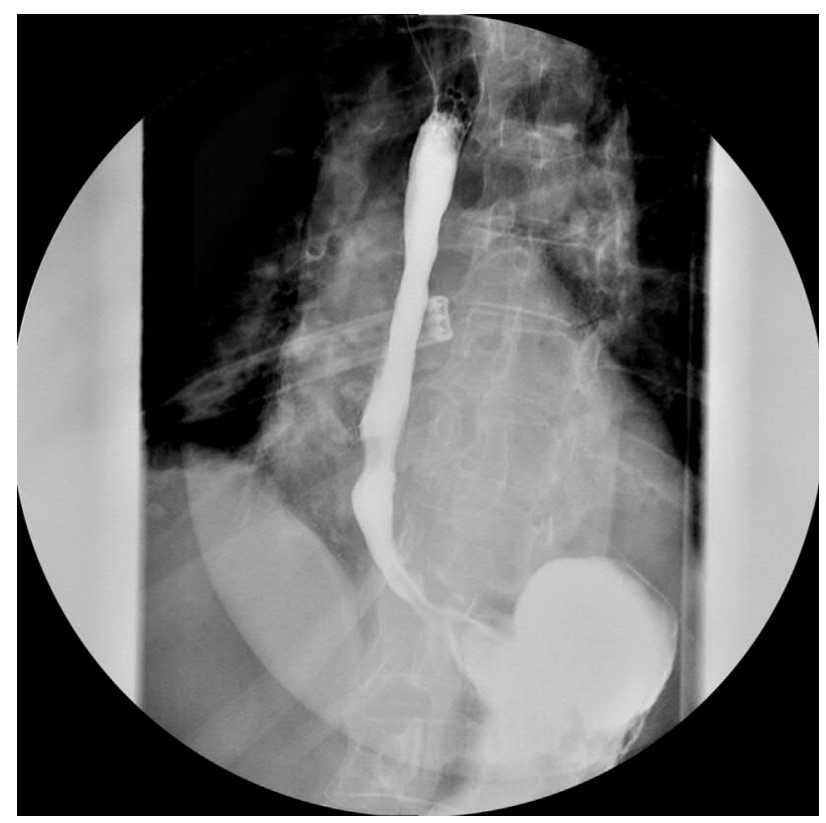

FIGURE 6. An esophagogram showing no diverticulum or leak 3 days after the operation.

to the chest wall that needed to be taken down. Pulsion diverticula are more common at this location; however, we did note all layers of the esophagus in the diverticulum (although the muscularis was attenuated), making this a true diverticulum.

There might also be some abnormalities in esophageal peristalsis at the time of the initial leak secondary to the inflammation in the area. Akin to changes in small bowel motility after resection, esophageal peristalsis may have been altered after perforation. We have no literature that sheds light on how esophageal peristalsis is affected by stent placement, but there may be some changes that need to be studied further.

Esophageal stents have changed the management of patients with esophageal perforations. In selected cases, they help to avoid major surgical interventions and the accompanying morbidity and mortality. Little is known, however, regarding the long-term complications of treating esophageal perforations with these minimally invasive approaches. In light of our findings, further studies looking at the early, intermediate, and long-term complications of esophageal stenting for the management of spontaneous perforation are needed to clearly establish the risk for poststent esophageal diverticulum formation.

We thank John Hagen for his excellent illustrations of the surgical procedure.

\section{References}

1. Tedesco P, Fisichella PM, Way LW, Patti MG. Cause and treatment of epiphrenic diverticula. Am J Surg. 2005;190:891-4.

2. Benacci JC, Deschamps C, Trastek VF, Allen MS, Daly RC, Pairolero PC Epiphrenic diverticulum: results of surgical treatment. Ann Thorac Surg. 1993; 55:1109-13; discussion 1114

3. Orringer MB. Epiphrenic diverticula: fact and fable. Ann Thorac Surg. 1993;55: 1067-8.

4. Kiernan PD, Sheridan MJ, Elster E, Rhee J, Collazo L, Byrne WD, et al. Thoracic esophageal perforations. South Med J. 2003;96:158-63.

5. Biancari F, D'Andrea V, Paone R, Di Marco C, Savino G, Koivukangas V, et al. Current treatment and outcome of esophageal perforations in adults: systematic review and meta-analysis of 75 studies. World J Surg. 2013;37:1051-9.

6. Schweigert M, Beattie R, Solymosi N, Booth K, Dubecz A, Muir A, et al. Endoscopic stent insertion versus primary operative management for spontaneous rupture of the esophagus (Boerhaave syndrome): an international study comparing the outcome. Am Surg. 2013;79:634-40.

7. Radecke K, Gerken G, Treichel U. Impact of a self-expanding, plastic esophageal stent on various esophageal stenoses, fistulas, and leakages: a single-center experience in 39 patients. Gastrointest Endosc. 2005;61:812-8.

\title{
Acute inferior wall myocardial infarction secondary to ruptured sinus of Valsalva aneurysm in a 22-year-old man
}

Hui-Ping Sun, MD, Xiang Ma, PhD, Xue Bai, MD, Karmacharya Ujit, MD, and Yi-Tong Ma, PhD, Ürümqi, China

\footnotetext{
From the First Affiliated Hospital of Xinjiang Medical University, and Xinjiang Key Laboratory of Cardiovascular Disease Research, Ürümqi, China.

Disclosures: Authors have nothing to disclose with regard to commercial support.

Hui-Ping Sun and Xiang Ma share the position of first author and they also share joint authorship.

Received for publication July 4, 2013; revisions received Aug 25, 2013; accepted for publication Sept 6, 2013; available ahead of print Oct 30, 2013.

Address for reprints: Yi-Tong $\mathrm{Ma}, \mathrm{PhD}$, Cardiology, First Affiliated Hospital of Xinjiang Medical University, Ürümqi, Xinjiang 830054, China (E-mail: myt-xj@163.com).

J Thorac Cardiovasc Surg 2014;147:e8-10

$0022-5223 / \$ 36.00$

Copyright (c) 2014 by The American Association for Thoracic Surgery

http://dx.doi.org/10.1016/j.jtcvs.2013.09.020
}

Sinus of Valsalva aneurysm (SVA), a rare condition of thinning of the wall of the aortic sinus, usually enlarges with time and remains undetected until rupture. After rupture, SVAs may protrude into any heart chamber, more commonly the right atrium or ventricle, or rupture into the pulmonary artery or interventricular septum. Those that remain unruptured are typically asymptomatic hence easily ignored. We report a case highlighting the importance of recognition of atypical manifestations of the disease. 

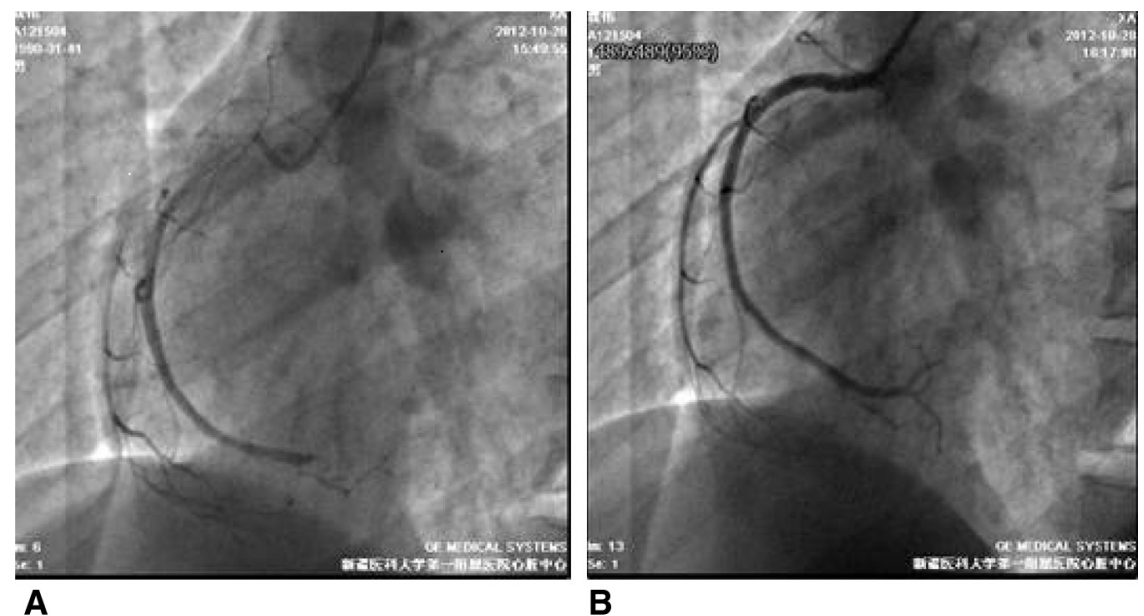

B

FIGURE 1. A, Occlusion of the distal right coronary artery. B, The distal right coronary artery is recanalized after the procedure, with blood flow at Thrombolysis In Myocardial Infarction level 3.

\section{CLINICAL SUMMARY}

A 22-year-old man without any significant medical, surgical, or family history of any cardiovascular disease, was driving a car when he suddenly felt chest discomfort (squeezing type radiating to inner part of left shoulder and upper arm), palpitations, profuse sweating, and transient loss of consciousness. He was brought to the emergency department, where on arrival his vital signs were stable. Results of general physical examination were normal except for a grade 2/6 diastolic murmur heard over the apex. Electrocardiography showed ST-segment elevation in leads II, III, and aVF. Echocardiography showed coronary artery disease manifestations. Laboratory findings showed a creatine kinase level of $67 \mathrm{IU} / \mathrm{L}$, a creatine kinase

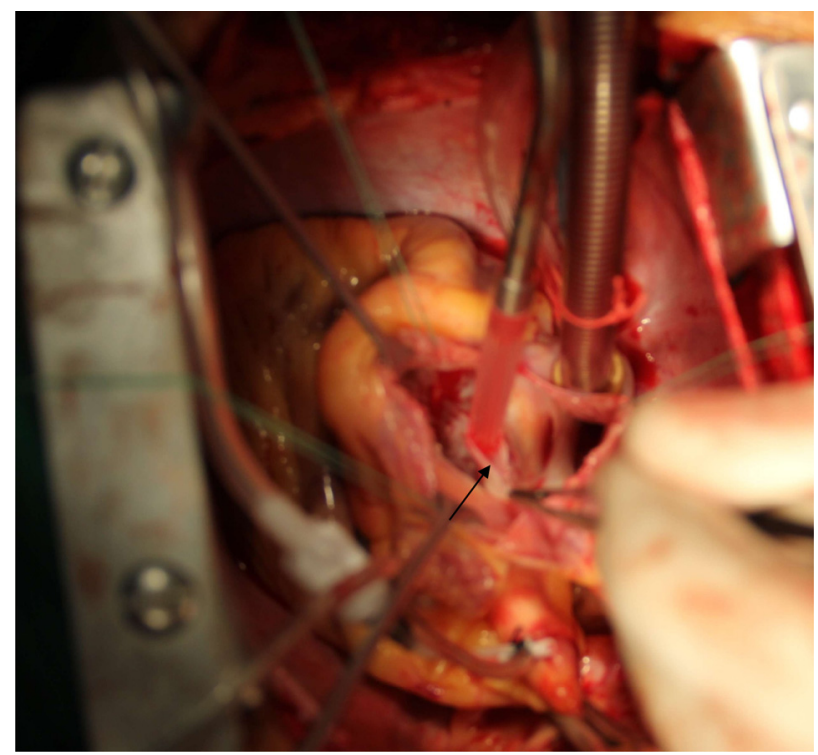

FIGURE 2. Operative view of the ruptured aneurysm of the sinus of Valsalva (arrow). isoenzyme MB level of $26.17 \mathrm{IU} / \mathrm{L}$, and a troponin I level of $0.13 \mathrm{ng} / \mathrm{mL}$. Acute inferior wall myocardial infarction (MI) was diagnosed, and the patient was transferred for percutaneous coronary intervention. Coronary angiography (Figure 1,A) showed occlusion in the distal right coronary artery (RCA). Percutaneous aspiration thrombectomy was done, and blood flow to the RCA was restored. Postprocedure coronary angiography showed successful revascularization without residual stenosis, and distal blood flow was evaluated at Thrombolysis In Myocardial Infarction level 3 (Figure 1, B), thus not necessitating coronary stent implantation. The patient's chest pain was relieved after the procedure; however, a grade $2 / 6$ diastolic murmur remained, warranting further evaluation. Echocardiography at this time showed aortic clover flap and ruptured right coronary sinus protruding into the right atrium $(0.7 \times 0.8 \mathrm{~cm})$. Color Doppler Flow imaging detected continuous shunt of the sinus into the right atrium from left to right, mainly during diastole. The clinical impression was a ruptured SVA. The patient was then shifted to the cardiac surgery unit for emergency repair. The intraoperative finding was a ruptured right coronary sinus protruding into the right atrium $(0.5 \times 0.6 \mathrm{~cm}$; Figure 2$)$, which was repaired successfully.

\section{DISCUSSION}

SVA is a rare condition resulting from an absence of normal elastic and muscular tissue, leading to thinning of the wall of the aortic sinus. SVAs usually enlarge with time and remain undetected until they rupture. Once ruptured, they can protrude into any of the heart chambers, usually the right atrium (as happened in this case) or the right ventricle. Occasionally, SVAs rupture into the pulmonary artery or interventricular septum. Those that remain unruptured are typically asymptomatic and thus easily ignored. 
This case highlights the importance of recognition of atypical manifestations of SVA, which may lead to missing a definite diagnosis at first assessment. In our case, the patient's primary diagnosis was acute inferior wall MI. This presentation, combined with electrocardopgraphic and coronary angiographic results, can easily mislead the physician to make a definite diagnosis of coronary artery disease and thus ignore further differential diagnosis, without probing into the potential cause of the acute MI. In this case, however, there were some clues. The patient was young, without any cardiometabolic risk factors or any atherosclerotic plaques on echocardiography and angiography, and the exact pathophysiologic mechanism of acute MI thus needed to be determined. Echocardiography plays a key role in the diagnosis of right SVA, determining the location and size of the rupture and demonstrating associated lesions. ${ }^{1}$ Although highly diagnostic, however, echocardiography is limited in both sensitivity and accuracy, especially in an emergency situation. In this case, because the primary impression was coronary artery disease, SVA went unnoticed at first glance, thus demonstrating the importance of including SVA in the differential diagnosis before performing echocardiography on a young individual without any cardiometabolic risks who has a sudden acute MI.

The proposed pathophysiologic mechanism in this case would be that the thrombus developed in the aneurysm of the right coronary sinus of Valsalva and traveled into the RCA once the aneurysm ruptured, in turn precipitating the acute MI. We can tell that the thrombus was not caused by atherosclerosis, because the proximal RCA showed no coronary artery disease changes during the angiographic procedure and the obstruction was very abrupt, thus reinforcing the theory of a thrombus traveling down the RCA. In addition, during an open cardiac procedure, it was observed that neither the SVA nor the right SVA affected the RCA, thus clarifying that the thrombosis of the RCA was related neither to aneurysmal compression of the RCA nor to the right SVA encroaching on the ostium of the RCA. It was also reported that there was thrombosis in the SVA that moved further and might become a source of cerebrovascular embolism, causing a thromboembolic cerebrovascular accident might occur. Shahrabani and colleagues ${ }^{2}$ described a young patient with a large unruptured aneurysm of the right sinus of Valsalva containing thrombus who had a history of cardiovascular accident caused by an embolus to the right middle cerebral artery. Similarly, Honda and coworkers ${ }^{3}$ and Luckraz and colleagues ${ }^{4}$ also reported SVA protruding into the pulmonary artery.

\section{References}

1. Attias D, Messika-Zeitoun D, Cachier A, Brochet E, Serfaty JM, Laissy JP, et al. A multi-perforated man: asymptomatic ruptured sinus of Valsalva aneurysm associated with an atrial and ventricular septal defect. Eur J Echocardiogr. 2008;9:301-2.

2. Shahrabani RM, Jairaj PS. Unruptured aneurysm of the sinus of Valsalva: a potential source of cerebrovascular embolism. Br Heart J. 1993;69:266-7.

3. Honda J, Yonaha T, Nakamura Y, Uechi N, Asato H. Ruptured aneurysm of the sinus of Valsalva protruding into the pulmonary artery. J Thorac Cardiovasc Surg. 2009;137:e37-9.

4. Luckraz H, Naik M, Jenkins G, Youhana A. Repair of a sinus of Valsalva aneurysm that had ruptured into the pulmonary artery. J Thorac Cardiovasc Surg. 2004;127: 1823-5.

\title{
Early structural valve deterioration of the Trifecta aortic valve biological prosthesis: A word of caution
}

\author{
Pankaj Saxena, FRACS, PhD, Kevin L. Greason, MD, and Hartzell V. Schaff, MD, Rochester, Minn
}

The St Jude Medical Inc (St Paul, Minn) Trifecta valve is a relatively new biological prosthesis that completed a multicenter US Food and Drug Administration Investigational Device Exemption study in 2011. During a median patient

From the Division of Cardiovascular Surgery, Mayo Clinic, Rochester, Minn. Disclosures: Authors have nothing to disclose with regard to commercial support. Received for publication April 7, 2013; revisions received July 14, 2013; accepted for publication July 19, 2013; available ahead of print Sept 16, 2013.

Address for reprints: Kevin L. Greason, MD, Division of Cardiovascular Surgery, Mayo Clinic, 200 First St SW, Rochester, MN 55905 (E-mail: greason.kevin@ mayo.edu).

J Thorac Cardiovasc Surg 2014;147:e10-11

$0022-5223 / \$ 36.00$

Copyright (c) 2014 by The American Association for Thoracic Surgery

http://dx.doi.org/10.1016/j.jtcvs.2013.07.053 follow-up of 0.9 years of the 1014 valve implantations in that study, 1 patient underwent explant of the valve for structural valve deterioration. ${ }^{1}$ We report an additional case.

\section{CLINICAL SUMMARY}

A 67-year-old woman presented to us with New York Heart Association class IV dyspnea and severe Trifecta prosthetic aortic valve stenosis. She had multiple previous cardiac operations that included an aortic valve replacement plus coronary artery bypass graft surgery 18 years previously, redo coronary artery bypass graft surgery 13 years previously, and repeat aortic valve replacement with a $21-\mathrm{mm}$ Trifecta valve 4 years previously. 